\title{
Book Review: Brown, James Dean. (2016) Introducing Needs Analysis and English for Specific Purposes. Oxford: Routledge, pp. 231.
}

\author{
Geraint Paul Rees ${ }^{1}$ \\ Universitat Pompeu Fabra
}

The worth of Needs Analysis (NA) to English for Specific Purposes (ESP) has been intrinsically understood since the 1960s. Some degree of analysis of students' communicative needs was implicit in early ESP textbooks, for example, A.J. Herbert's The Structure of Technical English (1965) considers that students need to be able "to follow the current literature in English in their particular subject" (back cover). Since then the term has undergone a change in scope from a straightforward consideration of learners' communicative needs to an evaluation of socio-cultural context in which these needs must be met, and the logistical factors that must be taken in account in meeting them. Today, NA has a central and explicit place in ESP and accounts for a great deal of practitioner research. A glance at the programme of any conference or continual professional development training course dealing with ESP professional practice will attest to a strong interest in NA on the part of trainee teachers, and teachers and administrators who conduct research. Introducing Needs Analysis and English for Specific Purposes is aimed at this audience.

The book is organised into three parts and seven chapters. Each part pertains to a major stage of the NA process. Each chapter represents an individual step in the process. Each chapter contains practical real-world examples of the problems commonly faced by needs analysts as well as didactic elements intended to guide the reader through the NA process. For example, preview questions give an initial indication of the material to be dealt with in the chapter helping the reader focus on

1 Corresponding author - Universitat Pompeu Fabra, Institut Universitari de Lingüística Aplicada (Centre específic de recerca) Departament de Traducció i Ciències fel Llenguatge (Spain).

Email: geraintpaul.rees@upf.edu 
the core task. Text boxes summarise the author's personal experiences while conducting NAs and provide a sense of the practical real-world contexts that needs analysts might find themselves in. Well-thought-out tasks provide the reader with opportunity for critical reflection on the material addressed. Finally, there are ample references which point the reader towards further information and key developments in the field.

As its name implies, the first section, 'Getting ready to do an ESP needs analysis' is concerned with the preparatory steps which must be undertaken before the NA can begin. Chapter 1, 'Defining needs analysis in English for specific purposes', begins by setting out what is understood by NA and ESP. NA is presented as primordial to ESP, "if there is no needs analysis, there is no ESP" (p.5). In an attempt to contextualise the field, the author presents a critique of the ways in which ESP is categorised, and ways in which the relationships between the various categories of ESP are understood. This prompts the realisation that, in practice there is always a limit to how specific a language course can reasonably be. A great deal of the literature on NA in ESP devotes considerable effort to describing changes in how NA and ESP have been understood over time, and the tension between ESP and general English. This is not the case here; context and theory are addressed in sufficient depth to provide an understanding of the place of NA and ESP in the general panorama of language teaching, without distracting from the practical aim of the book.

The concern for praxis is ever-present in this book. Having dealt with what might be understood by ESP, the author turns his attention to what is meant by needs analysis. In a didactic tone which typifies the book, there is a critical discussion of what different groups and stakeholders understand by needs and the practical implications of these viewpoints. Brown delimits four principal views of needs in NA in ESP: the democratic view which is narrowly defined as "whatever elements of the ESP the majority of students want" (p.13), the discrepancy view which involves examining discrepancies between what the ESP program requires students to do and what they need to do, the analytical view which involves looking to SLA theory for the logical next step in an ESP course, and the diagnostic view which entails deciding which "elements of ESP will cause the most harm if they are missing" (p.15). The author includes a personal reflection on the merits of each of these views before ending the discussion with a caution against a monolithic view of needs as synonymous with truth, arguing instead for a view of needs as "judgements and compromises justified by observations" (p.16). The discussion then turns to what might be understood by analysis in needs analysis and the limitations and practicalities that each view involves. Types of analysis addressed are: target situation analyses, present situation analyses, gap analyses, individual-differences analyses, rights analyses, various in-classroom analyses, means analyses, and language audits. This amounts to an overview of current debates about 
theoretical approaches to NA. Here again, there is an emphasis on a plurality of approaches.

Preparatory concerns continue in Chapter 2; 'Focusing the ESP needs analysis'. The first issue addressed is that of scale, examples provided range from narrow institutional NAs, to large-scale national and international efforts. Here again there is a strong emphasis on the practicalities of conducting NAs; financial and organisational considerations are highlighted. This is followed by a discussion of scope in NA. Since judgements about the scope of what can feasibly taught are likely to change as the NA progresses no precise formula is given. The discussion is limited to an enumeration of previously published NAs and their scope. The next chapter section is perhaps the most worthwhile for novice needs analysts. It comprises a classification of constraints on NAs: Situational constraints which range from socio-cultural, political, and budgetary concerns; to institutional organisational constraints such as the number of teaching hours and duration of courses; stakeholder constraints which include concerns such as students' fields of specialism, and level of English teachers' professional training, language proficiency, contract status, and attitude towards the $N A$, the attitude of administrators towards the NA, and finally the attitude of other stakeholders such as politicians, parents and subject area teachers. The final group of constraints, theoretical constraints, comprises those that occur when the various stakeholders have different beliefs about approaches to language learning and syllabus organisation. The chapter ends with a discussion of the different types of syllabuses in ESP and examples of how they might interact in practice to produce suitably varied and engaging courses.

Chapter 3, 'Selecting and sequencing ESP needs analysis data collection procedures', represents the final step in the NA preparation process. It situates appropriate datacollection procedures as the cornerstone of a successful NA. Choosing such procedures is a question of selecting relevant information which is both available and practicably obtainable. Following Berwick (1989), Brown presents six ways of planning education systems each of which is centred on a different type of information. After a short review of second language studies literature, six questions aimed at helping the analyst decide what types of information to gather are put forward. This is followed by a detailed critical discussion of 32 data-collection procedures apt for ESP NAs, and the benefits of drawing on many of these in combination. Technical discussion of data-collection procedures can often be daunting for novice researchers. The author avoids intimidating the audience by adopting a light anecdotal tone while still maintaining a thoroughgoing analysis of the advantages and potential pitfalls of each procedure. The only criticism here, albeit a slight one, is that there is no mention of need to consider how information will be analysed later in the NA process at this early stage. This omission might be intentional, so as not to stray from the step-by-step 
structure or the book, or perhaps so as not to alienate readers at an early stage of the NA process.

The second section of the book, 'Doing the ESP needs analysis', deals with the practical aspects of conducting NA fieldwork. Chapter 4, 'Collecting ESP needs analysis data, includes useful general strategies for building interpersonal relationships with the stakeholders: "Use whatever inside connections you have" (p.95) and "Remember to do three things: Listen, listen and listen" (p.96) are typical examples of the pragmatic advice provided. The pragmatic tone continues with strategies for conducting some of the 32 data-collection procedures outlined in Chapter 2. The section dealing with collecting NA data with questionnaires is particularly noteworthy, with practical advice for their effective creation and administration. The section dealing collecting NA data on ESP use amounts to an accessible guide to ethnography for early-stage needs analysts.

Chapter 5 deals with the analysis and interpretation of the data collected. The chapter begins with an examination of quantitative data analysis. In summarising the advantages of quantitative methods in NA, the author once again demonstrates an appreciation of the realpolitik of educational institutions: "Numbers carry weight with many audiences (especially certain kinds of administrators)" (p.123). A clear step-bystep guide to calculating and interpreting frequencies and percentages, and means and standard deviations using widely available spreadsheet software is provided. In this respect, the book goes beyond many similar introductory 'how-to' type books in applied linguistics in which such guides are often noticeably absent. However, there is no mention of statistical significance testing or indications on where to find information about such procedures. This would certainly be of use to both novice and accomplished needs analysts. A section on qualitative data analysis follows. Based on the work of Lynch (1997) and Miles and Huberman (1994; 1984) the section centres on the use of matrices for analysing ESP NA qualitative data. It gives examples of six different types of matrices and advice for spotting patterns in each of these. This section is supplemented by a section listing computer tools for qualitative data analysis. A distinction is made between 'general computer tools', perhaps the best known among these being ATLAS.ti, and tools for analysing corpora. The discussion of the latter group is very general and would be of limited use to a reader with any previous hands-on experience in corpus linguistics, however, it makes an adequate accessible and introduction for the uninitiated. The discussion focuses on four accessible, free-to-use corpus tools. The Sketch Engine (Kilgarriff, Rychlý, Smrž, \& Tugwell, 2004) is a notable omission here; it is web-based, easy-to-use, and available for free to teachers and students for a limited time period. It offers similar functionality as the other corpus tools mentioned yet is perhaps more user friendly. The overview of research tools is followed by a discussion of triangulation, the use of 
different sources and data-sets in conjunction, with the ultimate aim of increasing credibility of findings. Nine types of triangulation are discussed on detail. Although many how-to type research guides include some mention of triangulation it is rarely treated in such depth, or in such an accessible manner. The chapter finishes by discussing mixed-methods research techniques, which might be viewed as a natural extension of method triangulation. However, the author cautions against this view stressing the importance of not merely using different data sources, but also examining how they interact.

The third and final section of the book concerns the treatment of the data obtained in the NA process. Chapter 6 'Using the NA results in the rest of the curriculum', focuses on Student Learning Outcomes (SLOs). SLOs are organised on a continuum, ranging from those precisely defined in terms of audience, task, time-scale and manner; to experiential SLOs which simply state an experience that students should have during a course. Between these two extremes lies what the author terms 'Embedded SLOs' which only make sense the context of a particular ESP course. The section which follows contains detailed, clear, and well-thought-out instructions on writing and organising SLOs coherently. This advice is likely to be of great use, not only to needs analysts, but also to trainee language teachers. After this, the focus turns once again to a central concern of the book, obtaining stakeholder acceptance of NAs. There is a discussion of the challenges involved in getting teachers to accept NAs, and guidelines for overcoming these challenges. The chapter ends by highlighting the role of SLOs in other elements of the curriculum; including materials, assessments, teaching, and programme evaluation. This section could prove valuable to material designers, assessment designers, teachers and administrators.

Chapter 7 represents the practical endpoint of the NA process: 'Reporting on the ESP needs analysis project'. This section contains helpful advice on the organisation of the written NA report, how to reconcile the needs and expectations of a disparate audience of teachers, administrators and policymakers; and solid guidance about what information an NA report should contain. The latter is extremely well explained and exemplified and could equally be applied to other types of reports in the social sciences. The same can be said of the section on the practical considerations of publishing in academic journals and other academic volumes. The book ends with a reiteration of the limitations of any NA: "no single truth exists in any languageteaching situation" (P.203.), and the importance of teacher involvement in all aspects of the process.

Introducing Needs Analysis and English for Specific Purposes is a clear accessible guide to NA in ESP. Its tone is realist, anecdotal, and often witty, without patronising the reader. It is a grounded, realistic approach to the NA process, which make it an ideal step-by-step guide for teachers and curriculum developers doing NA in ESP. Its 
guidance for obtaining stakeholder support for the NA process is an element which is lacking in many other guides to NA and, as anyone with experience of carrying out NAs will attest, a difficult and often fraught part of the NA process. Moreover, perhaps as an unintended consequence of the perennial tension between specific purpose and general language courses, the book represents a solid, accessible resource for curriculum design in language teaching in general. More generally still, and excepting the omission of any mention of significance testing, it is a sound introduction to research methods in the social sciences in general, apt for both undergraduate and postgraduate students in need of a practical quick reference guide. Although set-out as a step-by-step process its chapters and chapter sections make sense as standalone units. The latter point is especially true of the sections on data-collection procedures and data-analysis. The book's broad appeal and clear jargon-free approach does not detract from its value as a guide for conducting considered and vigorous NAs.

\section{References}

Herbert, A. J. (1965). The Structure of Technical English. London: Longman.

Kilgarriff, A., Rychlý, P., Smrž, P., \& Tugwell, D. (2004). The Sketch Engine. In G. Williams \& S. Vessier (Eds.), Proceedings of the Eleventh EURALEX International Congress (pp. 105-116). Universite de Bretagne-Sud, Lorient: EURALEX.

Lynch, B. K. (1997). Language program evaluation: Theory and practice. Cambridge: Cambridge University Press.

Miles, M. B., \& Huberman, A. M. (1984). Qualitative Data Analysis. In Qualitative Data Analysis: A Sourcebook. Beverly Hills, CA: Sage

Miles, M. B., \& Huberman, A. M. (1994). Qualitative Data Analysis. In Qualitative Data Analysis: An Expanded Sourcebook. Beverly Hills, CA: Sage. 